\title{
Kerrang! magazine and the representation of heavy metal masculinities (1981-95)
}

\author{
Simon Jones \\ Leeds Arts University \\ Contact: Simon Jones, Senior Lecturer BA (hons) Graphic Design, Leeds Arts \\ University, Blenheim Walk, Leeds LS2 9AQ, United Kingdom. \\ E-mail: Simon.jones@leeds-art.ac.uk
}

\begin{abstract}
Metal magazines have been shown to play a significant role in communicating and shaping heavy metal culture. And, since the masculinist nature of heavy metal is perhaps its most discussed and agreed upon feature, scholars have argued that heavy metal magazines also reproduce masculine hegemony. Focussing on cover images from Kerrang! magazine, this study utilizes a mixed methods approach to examine how heavy metal masculinities are represented over an extended number of issues (from 1981 to 1995). Utilizing existing scholarship on heavy metal magazines and drawing on celebrity identification theory, I argue that many of the prevailing studies that discuss heavy metal masculinities are essentially flawed in their reliance upon particular traits. Instead I show the ways that media images can come to both reproduce and resist masculine gender norms in the context of heavy metal culture. By considering how representations are formed over an extended period and in relation to particular heavy metal icons, I show that certain arguments and assumptions about masculinity and male privilege in heavy metal culture are oversimplified.
\end{abstract}




\section{Introduction}

In 1981 Kerrang! magazine emerged as an A4-format glossy magazine focussing on heavy metal music. At the time, Kerrang! catered to a rising interest in heavy metal music in Britain - the so-called New Wave of British Heavy Metal. During this period, what I would classify as the magazine’s formative period, Kerrang! established itself as being the key media outlet in Britain catering towards the heavy metal subculture. From 1995, and the departure of Geoff Barton as editor, it was necessary that the magazine was rebranded and repositioned in order to adapt to the changing shape of metal music and culture (Ward n.d.). However, during this formative period 545 issues of Kerrang! were published, which helped to secure the magazine's position as a significant influencer within this heavy metal culture. This study focuses on this period of the magazine's history and considers how the images presented on the cover of the magazine come to represent what masculinity looks like within heavy metal culture.

Masculinity, or masculinism, is perhaps the most discussed (and agreed upon) feature of heavy metal culture besides the music. Most heavy metal scholars find consensus in the conclusion that heavy metal culture is built around a masculinist framework in which masculine ideals and norms are upheld and valorized by contrast to femininity. However, many of the researches that address heavy metal masculinities are supported through the use of descriptive traits, which, as I will show here, are inadequate in forming an accurate picture of what masculinity is and how it is enacted by heavy metal artists and fans. Traits are not used exclusively and rarely form any of the major arguments but instead seem to be used to allow readers to form mental pictures of what is being argued. Other approaches hone in on specific styles, mannerisms and behaviours 
communicated through music, videos, lyrics, media, etc. as a means of identifying evidence of heavy metal's masculinist undercurrent.

In this study I will be using quantitative and qualitative methods and drawing Brown’s (2007, 2010, 2016) research on heavy metal magazines and Brown’s (Fraser and Brown 2002; Brown and Fraser cited in Singhal 2003; Brown et al. 2003) theory of celebrity identification. I will explore to what extent the masculine traits used most commonly in heavy metal scholarship are depicted on the cover of Kerrang! magazine between 1981 and 1995 through which I will argue that the use of traits in describing heavy metal masculinities is largely inadequate. Following this, I will focus on specific heavy metal icons and their media personas as a means of demonstrating how these personas can both reproduce and resist heavy metal masculine norms. As such, I will also draw conclusions about how readers may interact with media images in understanding, negotiating and constructing their own identities.

\section{Theoretical contexts}

Weinstein (1991) and Brown (2010) show that to be rebellious and different (or 'alternative’) have become defining features of being in heavy metal. Both argue, albeit in different ways, that these features are so deeply rooted in the evolution of heavy metal culture that they have become ubiquitous. They both show that heavy metal culture is masculinist insofar as the features of heavy metal culture favour attitudes and characteristics that are typically coded as masculine (such as loudness and aggression). Although rebelliousness and self-marginalization (which is being alternative) are not used in the same sense as traits in the context of Weinstein and Brown's work, they do demonstrate that heavy metal's overtly masculinist ideology emerges neatly from these 
beginnings. Masculinism is seen as rebellious, given that blue-collar males experienced increasing economic and social marginalization (Weinstein 1991: 114), displays of masculinity, as Walser (1993: 109) argues act as a symbolic reclamation of patriarchal power. So, although rebellion and marginalization are not gender traits exactly, it seems important to consider how distinct gender roles and traits emerge from these ideological foundations.

The masculinist nature of heavy metal music and culture has been discussed and affirmed in many studies on the subject including Weinstein (1991), Vasan (2011), Nordstrom and Herz (2013) and Hill (2016) to name a few. Recent researches on heavy metal and gender (e.g. Vasan 2011; Nordstrom and Herz 2013) tend to draw on Weinstein (1991) and Walser’s (1993) seminal works, which had laid much groundwork for the analysis of heavy metal masculinities. Weinstein states that it is the 'special insecurities of youth' that heightens masculinity within heavy metal culture 'fortified in a historically specific way by the social, cultural, and economic marginalisation of white, blue-collar males' (Weinstein, 1991: 106). Further, Weinstein suggests that it was the 'rough and muscular work' undertaken by working classes that had defined masculinity (Weinstein, 2016: 13). For Walser, young working-class men living in western patriarchal societies are held ransom to expectations of masculinity and power, yet have no real resources to achieve this. Heavy metal, he says, 'has offered a variety of compensatory experiences and opportunities for bearing or resolving the contradictions of masculinity as they have been constructed by societies that are aligned by patriarchy...' (Walser, 1993: 110). 
Walser's analysis centres on a number of songs and videos and builds on prior research on the music video by E. Ann Kaplan, whose analysis of heavy metal music videos highlights what she calls the nihilistic mode of the music video, which is characterized by live performance, misogyny, sado-masochism, homoeroticism, anarchy and violence (1987: 55). Walser openly departs from Kaplan in a number of ways. Firstly, he states that Kaplan's use of the term 'nihilism' in relation to heavy metal videos diminishes their ideological function. He argues that the sexism in particular is a 'major ideological constituent of much heavy metal, but sexism is never nihilistic’ (Walser, 1993: 112). Secondly, he stresses that Kaplan’s observations of heavy metal music videos are made with no knowledge of heavy metal culture or audiences and are only activated within the context of MTV, which, Walser argues, plays only a very small role in heavy metal culture. Thirdly, and most importantly for Walser, Kaplan pays no regard to the music itself, which he sees as a deep methodological flaw. For Walser, this dismissal of the aural texts fails to acknowledge primary role that the music plays in 'invoking the libidinal and corporeal investment that intensifies belief, action, commitment and experience' (1993: 113).

The gendering processes theorized by Walser, namely misogyny, exscription, androgyny and romance, are arrived at through the analysis of a range of songs and videos. Although these examples are wide-ranging, the gendering processes that he addresses on a whole seem too generalized to be useful in a cultural context. Cope's (2010) book Black Sabbath and the Rise of Heavy Metal Music revisits and actively argues against Walser's analysis of heavy metal masculinities. Cope's criticisms of Walser's gender typologies offer some counter-arguments by focussing on particular 
examples (especially those found in the context of Black Sabbath) that he argues do not reflect Walser's ideas. However, although it is interesting to note how certain examples do not fit into these categories, Cope's arguments are not fully realized and do not offer anything new in exchange. Further, Cope’s approach rests upon the genre dichotomy of hard rock as being different to heavy metal in which he argues that many of Walser's masculinist arguments can be positioned as pertaining to hard rock rather than heavy metal. However, this approach is inevitably flawed because his arguments fail to see the diversities and complexities by which bands are adopted and/or rejected within heavy metal culture.

Exscription, in Walser's analysis, is situated as one of the key means by which masculine power is ensured in heavy metal culture. Exscription, being the 'total denial of gender anxieties through the articulation of fantastic worlds without women’ (1993: 110), is not pervasive though, there is certainly a female presence in heavy metal; however, Walser also addresses the means by which male power is assured in the presence of the female other - namely misogyny, sexualization and objectification. Besides those authors who have used Walser's theories directly, others have also discussed the marginalization and exclusion of women (Weinstein 1991; Hill 2016; Brown 2010; Nordstrom and Herz 2013; Vasan 2011) in heavy metal music and culture. Each of the authors concludes, in their own ways, that in order to establish their membership in heavy metal culture women must also negotiate their femininity. Weinstein asserts that heavy metal's marginalization of women is less to do with misogyny directly rather than 'a rejection of the cultural values associated with femininity' (1991: 67), a point echoed by Hill (2016), who suggests that the social constructions of femininity imposed on women set them at an 
immediate disadvantage in regard to heavy metal membership. Hill (2016), Nordstrom and Herz (2013) and Vasan (2011) each discusses the numerous strategies by which female participants in heavy metal culture negotiate their sense of gender around the prevailing masculinist ideologies of heavy metal culture. Two major modes of negotiated heavy metal femininity emerge from these discussions - those that maintain their femininity at the cost of tolerating misogyny and sexism and those that adopt and conform to more masculinized gender codes. However, Hill (2016: 152) maintains that although she affirms sexism and misogyny in heavy metal culture, her research has found that women's experience of sexism in heavy metal culture is less than that experienced in other contexts. Although the authors above do much to shed light on the ways that women perform gender in heavy metal contexts, the role of men in heavy metal is often situated as being stable in comparison (e.g. Nordstrom and Herz 2013: 465; Hill 2016: 106, 129). Although gender as a social construct is emphasized, the experience of male heavy metal fans, as being in receipt of masculinity, seems relatively trouble-free and given as stable. Of course, and especially for empirical work (Hill 2016; Vasan 2011; Nordstrom and Herz 2013), the experiences of male heavy metal fans are not their primary concern; however, the positioning of male heavy metal fans (as contrasting to female fans) often assumes a privileged position.

Other authors have also problematized theoretical positions that argue overt masculine authority in heavy metal by drawing attention to: methodological issues (Clifford-Napoleone 2015; Hill 2016), reliance upon a priori assumptions of gender roles and codes (Riches et al. 2014; Riches 2015), and, in the case of Cope (2010) highlighting the inaccuracies of Walser's typologies. Although confirming the predominantly 
masculinized nature of heavy metal music and culture, Riches (2015) and Riches et al.'s (2014) work emphasizes how in the context of the heavy metal concert (and particularly mosh pit activities) predefined gender roles are transgressed when women engage in the mosh pit. She departs from many of the preceding work on heavy metal and gender arguing that by making 'physical exertion, power, aggression, anger, pain and heavy metal identities only intelligible on the male body it inevitably marginalises women' (Riches et al., 2014: 265). Hill (2016: 129-30) echoes Riches’ point confirming that particular qualities of heavy metal that are presumed to be masculine-coded are not exclusively available to men. Hill and Riches reaffirm that such qualities are socially coded and not natural and they both suggest that disruptions to these codes can and do happen within the context of heavy metal.

Sam De Boise’s (2015) book Men, Masculinity, Music and Emotions, although not directly concerned with heavy metal music, draws attention to the faulty foundations by which many agreed notions of gender differences are conceived upon. De Boise’s book uses music as a case study to highlight the insufficiencies of existing research on the role of emotions in gender. His overarching discussion is not concerned with heavy metal or even music directly rather methodologically he addresses the issues surrounding preconceived associations of gender and emotions through studying how people listen to music. De Boise adopts a critical framework that casts doubt on the assuredness of existing ideas about gender roles and relationships. He argues that we should not think of gender relations in binary terms, 'but as indeterminate, structuring relations between bodies which, though durable, are capable of innumerable new potential means of becoming' (De Boise, 2015: 187). 
Clifford-Napoleone’s (2015) Queerness in Heavy Metal Music is perhaps the most divergent work on heavy metal and gender. She openly departs from both Walser and Weinstein who she sees as having reduced the potential of heavy metal scholarship by emphasizing only a limited scope of gender (Clifford-Napoleone, 2015: 3) and presume a heterosexual fan base (Clifford-Napoleone, 2015: 11). Her adoption of gender performativity is much more explicit and determined than many of the other writers on heavy metal who continue to struggle to detach biology, gender and (hetero)sexuality. As she says, heavy metal masculinity is 'nothing more than a drag show' (CliffordNapoleone, 2015: 11). She also delivers an alternative history of heavy metal culture, which is explained through an exploration of heavy metal's hallmark style codes focussing particularly on leather. She argues that leather styles in heavy metal were borrowed more from leather/BDSM culture than bikers (as proposed by Weinstein [1991]). Clifford-Napoleone employs a theoretical framework based around queerscape theory arguing that approaches that use either scene or subcultural theory are inadequate in describing the queering of heavy metal. Her use of this term breaks apart any conclusion of heavy metal as having a cohesive or singular structure. Instead, she speaks of heavy metal as having layers of scenes and subcultures within which 'lies a field of possibilities that allow queer fans to reterritorialise heavy metal' (Clifford-Napoleone, 2015: 19). Clifford-Napoleone emphasizes how queer subjects navigate, recycle, negotiate and construct their identities within heavy metal queerscapes; however, this process is not seen as a negative process but one in which territories are claimed by queer fans but are not visible to others (Clifford-Napoleone, 2015: 20). She says, 'heavy metal was always a place of queer connections, rendered unintelligible to the heteronormative 
world' (Clifford-Napoleone, 2015: 38). Her book casts significant doubt on the power and pervasiveness that is frequently associated with masculinity and heteronormativity in heavy metal culture. She does not deny that heavy metal music and culture in practice is manifestly patriarchal and heteronormative (as are most parts of western societies) but by breaking apart the structures of heavy metal culture using queerscape theory she leaves open opportunities for reinterpreting gender in heavy metal.

Glam-metal has proven to be a popular discussion point in heavy metal scholarship. This is no doubt owing to the androgynous (Walser 1993) approach to gender enacted by its performers - 'feminised' looks often offset against misogyny (Sollee 2011). The looks of glam-metal are all seen to be borrowed from feminine aesthetic practices (Weinstein 2016; Walser 1993; Coates 1997). Walser understands glam-metal's androgyny as 'yet another tactic for dealing with the anxieties of masculinity' (Walser, 1993: 128). Walser and Coates (1997: 56) both argue that the use of androgyny is a tactic of appropriation whereby feminine signifiers are adopted into masculinity in order to diminish the feminine threat. Yet, for Weinstein (2016: 13-14), androgyny in heavy metal is a form of deconstruction insofar as it breaks down the binaries of masculinity and femininity. Sollee’s (2011) analysis mirrors Weinstein’s deconstructionist interpretation in the sense that she emphasizes a blurring of gender binaries. However, Sollee describes this using a Freudo-Lacanian framework focussing particularly on hysteria. Hysteria, characterized fundamentally as being an unconscious antagonism of masculine and feminine motivations, is brought into conscious life in Sollee's analysis through the gender-bending behaviour in glam-metal. So, glam-metal styles and performances can be interpreted as either sustaining gender inequalities 
through the appropriation of feminine signifiers (Walser 1993; Coates 2007) or as challenging gender norms through experimentation and gender play (Weinstein 2016; Sollee 2011). Positively, Walser does suggest that glam-metal demonstrates 'the mutability of gender, by revealing the potential instability of the semiotic or symbolic realms that support current gender configurations' (1993: 131). So, although Walser is steadfast in arguing how glam-metal, like all heavy metal, 'replicates the dominant sexism of contemporary society’ (1993: 131), he does concede that heavy metal can also provide opportunities to experiment and disrupt traditional modes of gender.

The role of magazines within heavy metal culture has been explored by Weinstein (1991), Brown (2007, 2010, 2016) and Hill (2016). Each highlights how magazines come to constitute and reinforce the values of heavy metal culture. This is done through their textual strategies (Brown 2007), their modes of address (Brown 2010), abundant use of photography (Weinstein 1991) and the reification of prevailing heavy metal cultural myths (Hill 2016). Brown shows that the design, editorial and overarching structural strategies of heavy metal magazines act to embody and reinforce some of the most highly guarded values of heavy metal culture. The authors all point to the reciprocal and deliberative mode of address preferred by heavy metal magazines highlighted particularly through reader contributions. Brown (2010) and Hill (2016) especially argue that these strategies form a powerful bond between readers and the magazines in which the magazines become a forum for the discussion and negotiation of the particularities of heavy metal culture. Brown argues this by highlighting the position that heavy metal magazines operate, which rests in between music journalism and lifestyle media, but Hill (2016: 53-63) elaborates further by suggesting that this connection is enforced by the 
reified status of equality coded throughout the magazines’ modes of address. In examining Kerrang! specifically, Hill argues that a number of dominant myths about heavy metal culture are continuously enforced and sustained throughout its pages: equality, authenticity, the male warrior and the female groupie. Hill's theoretical framework, being that of the imaginary community, highlights the ways that community bonds are ensured through imagined social connections. This enables Hill to show how the perceived reciprocity and egalitarianism encoded in magazines such as Kerrang! are so powerful that they are held to be self-evident to the extent that to question them 'means challenging the whole culture of the hard rock and metal genre' (2016: 75).

Hill's analysis of, what she calls, the dominant myth of the male 'warrior' rests on her analysis of a depiction of Machine Head's Robb Flynn as being an exemplar of this myth pictorially coded. However, this analysis is quite limited in that a quite wide range of visual signifiers are defined as being warrior-like without much reasoning and explanation. The difficulty here is that, especially with such a range of signifying elements, many more potential readings are also possible. Hill actually admits that this approach is problematic if we consider audiences to be active participants in meaningmaking (2016: 76) (which would prevent any single reading being possible), which in a sense nullifies her previous analysis. Although she stresses that myths such as this are the dominant representations and certainly not the only ones (2016: 76), her arguments do rest on these myths having a powerful effect on the readership. Both Brown and Hill employ strategies that focus predominantly on reader content and those aspects that explore images draw attention to dominant readings and do not address other ways that readers may interpret images. Also, they do not consider the relative potency and impact 
that images can have depending on the popularity of the individual depicted, where it is situated in the magazine and the diverse ways that readers use image content in relation to their own experiences.

Hill's analysis of the prevalent myths found in Kerrang! magazine is balanced with a consideration of how female fans and readers may position themselves in relation to these. However, what is missing to any significant degree is how male readers interpret and respond to the same myths. It can also be troubling for men to be burdened by stifling and restrictive expectations of their gender and although efforts are taken to separate biology and gender, themes related to masculinity are often automatically positioned as naturally male. For instance, Hill argues that 'opportunities of performing masculinity are so evidently more open to men - trained to do it throughout their lives’ (2016: 67) and 'women's readings would require more negotiation as they are asked to identify against themselves' (2016: 77). This conclusion is troubling because it suggests that no negotiating is done by male fans in order to align with the gender codes of heavy metal culture and that, perceivably, male fans can just be their natural selves without being subject to scrutiny. Furthermore, heavy metal culture, according to Weinstein (2016), has been a place where alternative gender modes have been freely adopted and experimented with and it seems appropriate to assume that an amount of reflexive gender negotiating has been involved in these sorts of gender play. In heavy metal scholarship, masculine identities are often depicted as being static and ideologically enforced through the frequent reliance upon traits (such as machismo, toughness, aggression) and typologies (e.g. Hill's warrior and Walser's exscription and androgyny) that inherently do not accommodate for more flexible interpretations of gender identities. Although Hill (2016) 
and Walser (1993) both emphasize the complexities involved in analysing heavy metalgender relations, they both rely heavily on traits, which are inherently static and dependent upon pre-existing gender codes. Weinstein (2016) and Clifford-Napoleone (2015) on the other hand demonstrate that negotiation, play and reflexivity are much more vital in considering gender positioning in heavy metal.

\section{Lines of inquiry}

The literature review above has hopefully revealed some concerns surrounding (a) how masculinities are theorized in heavy metal scholarship and (b) how media images interact with the masculinist ideologies of heavy metal culture. This study will address some of these concerns through the following aims:

1. How frequently and accurately are masculine traits (suggested in existing heavy metal scholarship) represented in heavy metal magazines over an extended number of issues?

2. Do media representations of heavy metal masculinities present potential opportunities to re-negotiate, experiment with or question existing gender categories within heavy metal culture?

\section{Methods}

This study utilizes cover images from back issues1 of Kerrang! magazine as being a pervasive authority on heavy metal music and culture (Weinstein 1991; Brown 2007; Hill 2016). I have isolated a specific period in the magazine's history (1981-1995) for this analysis. This period represents the formative stage in Kerrang! magazine’s long history and the period overseen by Geoff Barton and editor. In this sense, many of the magazine's textual strategies were established and developed throughout this period. This 
period in heavy metal's history is also important since it saw the first academic interests in heavy metal (noted here Weinstein 1991; Walser 1993) and heavy metal growing into an immensely popular and global genre. Most importantly, focussing on this particular period of heavy metal history allows me to accurately unpick and analyse particular masculine traits at a time when they were more distinct and less fragmented.

I will be employing a mix of quantitative and qualitative approaches in this study using content and textual analyses. The content analysis method is used here as a means of assessing the frequency and accuracy by which the identified masculine traits are represented and reproduced on the cover of Kerrang! magazine.2 A total of fifteen features were identified and coded3 in the content analysis. These were divided into eight stylistic features taken from the literature, one additional stylistic feature added by the author and four performative features taken from the literature (see Table 1).

Table 1: List of masculine traits and sources

\begin{tabular}{|l|l|}
\hline Traits & Source \\
\hline Stylistic traits & $\begin{array}{l}\text { (Weinstein 1991; Cohen 1997; Walser 1993; Clifford- } \\
\text { Napoleone 2015) }\end{array}$ \\
\hline Leather & (Cohen 1997) \\
\hline Denim & $\begin{array}{l}\text { (Weinstein 1991; Coates 1997; Walser 1993; Nordstrom } \\
\text { and Herz 2013; Sollee 2011) }\end{array}$ \\
\hline Elaborate hair & (Weinstein 1991; Walser 1993) \\
\hline Long hair & (Weinstein 1991; Coates 1997; Schippers 2002), \\
\hline Tight clothes & $\begin{array}{l}\text { Weinstein 1991; Walser 1993; Schippers 2002; } \\
\text { Nordstrom and Herz 2013) }\end{array}$ \\
\hline Make-up & (Weinstein 1991; Walser 1993) \\
\hline Elaborate clothing & (Weinstein 1991; Hill 2016) \\
\hline Tattoos & Identified by the author \\
\hline Exposed flesh & \\
\hline Behavioural traits & \\
\hline
\end{tabular}




\begin{tabular}{|l|l|}
\hline Macho & $\begin{array}{l}\text { (Weinstein 1991; Cohen 1997; Beyton 1997; Walser } \\
\text { 1993; Riches 2015; Nordstrom and Herz 2013; Hill } \\
\text { 2016) }\end{array}$ \\
\hline Corporeal energy* & (Beyton 1997; Walser 1993) \\
\hline Hyper-masculinity & (Walser 1993; Weinstein 1991; Sollee 2011) \\
\hline Androgyny & (Walser 1993; Weinstein 1991; Sollee 2011) \\
\hline Madness & (Walser 1993; Weinstein 1991) \\
\hline Horror & (Walser 1993; Weinstein 1991) \\
\hline
\end{tabular}

*This feature was dropped from the analysis after drawing insufficient inter-coder reliability.

The subsequent qualitative analysis focuses on a considered selection cover images features three prominent heavy metal icons (Ozzy Osbourne, Jon Bon Jovi and Scott Ian). This part of the study uses textual analysis and draws on celebrity identification theory proposed by Brown and colleagues (Brown and Fraser 2002; Singhal et al. 2003; Brown et al. 2003). In this discussion the artists mentioned above are considered as celebrities and positioned in relation to the identification model set out by Brown et al. Celebrity status is achieved through their extensive media exposure and artist status within heavy metal culture. According to Dyer (1998) celebrity is discursively constructed through the intersections of a variety of media depictions. Although I remain restricted to a single magazine, I have selected five separate cover images of each person as being representative of the discursive construction of their celebrity image over time. Thus, drawing on celebrity identification theory I will analyse several cover images 4 featuring each of the three artists in considering how their mediated images may reproduce or resist traditional gender roles and how these may influence audience values and behaviours. 
The selection of artists identified here are representatives of the variety of heavy metal styles active at the time both musically and in relation to subgenre social codes. Each has also garnered a significant notoriety and status within heavy metal in general and in relation to their specific subgenres. Ozzy Osbourne in particular is possibly the most well-known celebrity figure of the heavy metal world having played a role in the genesis of the heavy metal genre. Although Tony Iommi and Geezer Butler have played more important roles in the musical and thematic development of Black Sabbath, Osbourne has certainly received the lion's share of media attention and notoriety within the scene. Osbourne's continuing appeal has been forged through the development of a public persona that, in many ways, denies the prevalent modes of heavy metal masculinities.5 Osbourne played on his smaller stature and the dark themes associated with Black Sabbath in developing a public persona based around madness and themes of horror. In contrast to Osbourne, Jon Bon Jovi was the central proponent of the band Bon Jovi and well-equipped musically and in performance. Jon Bon Jovi is used in this context as being representative of the 'lite-metal' subgenre. Bon Jovi achieved huge success with their eclectic sound that, according to Walser, 'managed to combine the power and freedom offered by metal with the constructed "authenticity” of rock, and, most important, the romantic sincerity of a long tradition of pop' (1993: 120). Walser uses Bon Jovi in formulating his 'romance' gender typology in which he suggests that 'Jon Bon Jovi [...] projected a kind of sincerity and romantic vulnerability that had enormous appeal for female fans' and Bon Jovi’s music 'helped to transform what had long been a mostly male subcultural genre into a much more popular style with a genderbalanced audience' (1993: 120). Notwithstanding his supposed appeal to female fans, Jon 
Bon Jovi also provided opportunities for male fans to reflect on their own gender identities in light of his popularity and feminine appeal. Whilst this sort of 'romantic vulnerability’ may certainly be appealing to some male fans, 6 it may also present opportunities in courtship. Scott Ian stands out in this trio insofar as he and his band Anthrax had not been known to heavy metal media for quite the same duration. That being said, Scott Ian presents an interesting dimension to a study of heavy metal masculinities in several ways. Firstly, Ian is the most featured member of Anthrax on the cover of Kerrang! magazine and although this is no doubt due to his position as the founding member of the band and the fact that Anthrax had gone through several vocalists in the early stages of the bands genesis, it is not common for a non-frontman member of a band to retain media focus. Secondly, throughout the early stages of Anthrax's success, Ian had apparently experienced male pattern baldness. Although not uncommon and certainly not a serious concern, Ian's adoption of a shaved head appearance presented a very different look in contrast to the long hair most associated with heavy metal. Thirdly, Scott Ian's role as a guitarist rather than non-instrumental performer meant that, in concert, Ian's performance was centred around his instrumentation primarily and less so his body. This translates to a sort of awkwardness in photo shoots that is not seen as much in frontmen. Thus, these artists were selected for this part of the study because they each, in their own distinct ways, have achieved notable renown within heavy metal and simultaneously offer opportunities of exploring the diversities of heavy metal masculinities that are all-to-often withheld from heavy metal scholarship.

\section{Content analysis results}


Of the total usable images (373) 62\% were made up of single male photographed subjects, only $2 \%$ contained images of women (either singly or in groups), and $36 \%$ contained either images of multiple males or images of non-photographic content. The almost complete exclusion of women from Kerrang! magazine’s cover images during this period as well as the reluctance to show any sort of gender cohesion (other than via illustrated content) supports Walser's (1993: 114-17) idea of the 'exscription' of the feminine within heavy metal culture.

Table 2: Frequency and percentage of male/female subjects in the total usable cover images

\begin{tabular}{|l|l|l|}
\hline Category & Quantity & Percent \\
\hline Sole-male subjects & 231 & 62 \\
\hline Female subject (single or in groups) & 7 & 2 \\
\hline $\begin{array}{l}\text { Other (groups of males, non-photographic, non- } \\
\text { visible) }\end{array}$ & 135 & 36 \\
\hline Total n & 373 & \\
\hline
\end{tabular}

Of the stylistic traits identified only long hair and elaborate clothing presented with statistically significant results.7 The presence of long hair stands out here as being the most pervasive stylistic feature of the heavy metal look (see Table 3). Furthermore, the feature identified by the author as 'exposed flesh' also showed significant results (47 per cent in any amount of exposed flesh beyond normal expectations - see Table 4). Exposing flesh, especially upper body and upper arms, can be read as a presentation of traditional masculinity in that muscularity or body hair may be emphasized both of which are clear signifiers of masculinity. Although the other traits appeared in at least some of the sample images, they did not show significant frequency. This would seem to suggest that significance attributed to these traits by authors is not in their sustained presence. 
This is not particularly unusual since it is accepted that frequency of appearance is not the only one way that a particular trait could become known as a significant feature.

However, it does perhaps highlight an issue of concern regarding how particular features are deemed to be significant by scholars if they are not significant in frequency. 8 Although traits appear in heavy metal scholarship among more discussion and detail surrounding gender issues, these discussions are often enriched by the identification of traits. The use of traits in heavy metal research provides visual signs for the reader of how gender is performed in the context of heavy metal; however, the results here present a much clearer picture of how often and clearly these traits appear in specific contexts.

Table 3: Frequency (and percentage) of stylistic features present in sample ( $\mathrm{n}=138)$

\begin{tabular}{|l|l|l|l|l|l|l|l|l|}
\hline Category & Leather & Denim & $\begin{array}{l}\text { Elaborate } \\
\text { hair }\end{array}$ & $\begin{array}{l}\text { Long } \\
\text { hair }\end{array}$ & $\begin{array}{l}\text { Tight } \\
\text { clothes }\end{array}$ & $\begin{array}{l}\text { Make- } \\
\text { up }\end{array}$ & $\begin{array}{l}\text { Elaborate } \\
\text { clothing }\end{array}$ & Tattoos \\
\hline Present & $\begin{array}{l}26 \\
(19)^{*}\end{array}$ & $\begin{array}{l}15 \\
(11)^{*}\end{array}$ & $29(21)$ & $107(78)$ & $27(20)$ & $16(12)$ & $53(38)$ & $22(16)$ \\
\hline Absent & $\begin{array}{l}112 \\
(81)\end{array}$ & $\begin{array}{l}123 \\
(89)\end{array}$ & $109(79)$ & $31(22)$ & $111(80)$ & $\begin{array}{l}122 \\
(88)\end{array}$ & $85(62)$ & $\begin{array}{l}116 \\
(84)\end{array}$ \\
\hline
\end{tabular}

*Together, either leather or denim or both were present in 30 per cent of the sample.

Table 4: Frequency (and percentage) of stylistic features identified by author present in sample $(\mathrm{n}=138)$

\begin{tabular}{|l|l|}
\hline Category: & $\begin{array}{l}\text { Exposed } \\
\text { flesh }\end{array}$ \\
\hline Chest & $15(11)^{*}$ \\
\hline Arms & $27(20)^{*}$ \\
\hline Full upper body & $13(9)^{*}$ \\
\hline Other & $10(7)^{*}$ \\
\hline None & $73(53)$ \\
\hline
\end{tabular}

*Together, any part of exposed flesh other than hands, face, neck, etc. was present in 47 per cent of the sample. 
Other than in the contexts of glam-metal androgyny, machismo is used most (Weinstein 1991; Walser 1993; Brown cited in Scott and Von Helden 2010; Riches 2015; Hill 2016) in describing heavy metal masculine performance. Discussions concerning masculine pride and the embellishment or emphasis of typically masculine characteristics are encapsulated into the term 'machismo' (as well as exact uses of this word); however, other aspects, such as exscription, sexism, misogyny, violence, aggression, etc., may also be defined in the same way since they all seek to emphasize masculine power first and foremost. Displays of machismo were indeed present in the images to a fairly significant degree (38 per cent); however, considering the frequency that it did not appear (62 per cent) may be more enlightening in this context. Considering the sustained emphasis of machismo in heavy metal scholarship one would expect to see more consistent signs of this feature represented on the cover of Kerrang! magazine (perhaps even more so in this period of heavy metal history). Of course, what this content analysis does not show is what is being presented in place of machismo. In this sense, there could be a number of other ways in which masculine power is sustained in this context.

Table 5: Frequency (and percentage) of performative features present in sample ( $\mathrm{n}=138)$

\begin{tabular}{|l|l|l|l|l|l|}
\hline Category & Machismo & Madness & Horror & & $\begin{array}{l}\text { Gender } \\
\text { spectacle }\end{array}$ \\
\hline Present & $52(38)$ & $36(26)$ & $7(5)$ & $\begin{array}{l}\text { Hyper- } \\
\text { masculine }\end{array}$ & $30(22)$ \\
\hline Absent & $86(62)$ & $102(74)$ & $131(95)$ & Androgyny & $25(18)$ \\
\hline $\begin{array}{l}\text { Neither / } \\
\text { unidentifiable }\end{array}$ & & & & Neither & $83(60)$ \\
\hline
\end{tabular}

*Any exposed flesh was recorded in 47 per cent of the sample. 
Hyper-masculinity, in the context of this content analysis, is defined in a very similar way to machismo but is reserved for the most extreme or over-displays of masculinity. In this way, it is likely that all instances of hyper-masculinity would also be recorded as macho but not all instances of macho would be recorded as hypermasculine. For instance, issue 291 featuring James Hetfield of Metallica (Figure 1) would be coded as macho on accounts of his stoic posture and expression whilst issue 182 featuring Joe Elliott of Deff Leppard (Figure 2) would be coded as hypermasculine due to the aggressive energy of his posture and facial expression. In contrast to hypermasculinity, instances of androgyny were recorded when male performers adopted the feminine appearances typically associated with glam-metal. The results for androgyny found here are reflective of glam-metal's status within the heavy metal scene. Of course, in between machismo, androgyny and hypermasculinity, there are still many instances that could not be easily coded. In these circumstances the subject of the image presented no clear signs of feminine appearances, macho postures or facial expressions, or any aggressive posturing.

What I hope is highlighted through these results is that although certain masculine traits may find particular focus in heavy metal scholarship, this does not necessarily translate in the frequencies that they appear in heavy metal magazines. That is not to say that their arguments are incorrect rather, if an author were to employ the use of traits in their analysis, then there should be demonstrated an awareness of how, if not through repeated exposure, these traits come to represent what masculinity means in the context of heavy metal. Authors such as Clifford-Napoleone (2015), Riches (2016) and De Boise 
(2015) have in many ways shown the potential for approaches to gender analysis that are less static and allow interpretations that can secede from rigid gender formulas. I hope this content analysis shows some support for this position insofar as it has highlighted how frequently (or infrequently) particular traits are manifested in media texts and questions by what means certain traits are established. I will now look more closely at a small sample of individual cover images focussing on three well-established heavy metal icons in order to demonstrate how particular individuals can become influential to how the gender codes of heavy metal are reproduced or resisted.

\section{Heavy metal masculinities and celebrity identification}

I have suggested here that the specificity of traits as a means of describing gender identities is insufficient when looking at how representations are presented over an extended period.9 Whilst the content analysis showed that the traits discussed were represented, the frequencies recorded were perhaps not as significant as the critical research would predict. So, by what means then, do these images come to represent and construct the ideologies of heavy metal culture? To address this I turn to the theory of celebrity identification discussed by Brown and colleagues. Brown et al. consider celebrity identification to be the 'process by which audience members seek to adopt the values, beliefs, or behaviour of well-known public figures’ (Brown and Fraser, 2003: 105). The authors argue that celebrity identification is different to, yet preceded by parasocial interactions with celebrity figures. Parasocial interactions (such as using the celebrity's first name and taking an interest in their personality, style, etc.) differ from identification since 'developing a relationship with a person and wanting to be like that 
other person are two different matters’ (2003: 103-04). Yet these interactions are the necessary beginnings of identification. Brown and Fraser (2003: 107-08) stress that media exposure is a necessary precursor to parasocial interaction and identification, which, in a sense, highlights the role that frequency plays in constructing powerful media images. The authors also argue that identification is dependent upon the longevity of the celebrity’s public life as well as whether the celebrity is perceived to be a positive or negative role model. The authors stress however, that what constitutes positive or negative is culturally dependent and subject to changes (2003 106). This is particularly apparent in the case of heavy metal since, in its early stages, heavy metal was the target of much public shaming particularly in the United States. However, to heavy metal fans, positive attributes such as musical talent, confidence, freedom and power would no doubt make heavy metal stars appealing. What is also quite illuminating in celebrity identification theory is the emphasis of reciprocity in the process of identification. Although the process defines the ways that values and behaviours can be influenced by media representations, they argue that identification is dependent on the audience member seeing something in the celebrity figure. That is, 'an individual may be attracted to a particular celebrity because of a sense of sharing values with that person' (Fraser and Brown 2002: 189). In this sense, the process of identification entails the audience’s involvement that is more than a simple compliance. In this sense, a heavy metal icon must present themselves as embodying certain values of heavy metal culture in order to attract appeal from fans whilst fans will likely seek credentials in the artist's ability to uphold heavy metal values. 
So, through celebrity identification theory, I suggest that there are ways in which certain aspects of heavy metal masculine practices can be reproduced and constructed via media images without the need for excess saturation. This is achieved through the popularity of individual heavy metal stars and their ability to garner connections with fans that evolve beyond spectacle or entertainment to parasocial relationships and identification. By exploring images of heavy metal stars that have gained significant celebrity status within heavy metal in general and within subgenre contexts, I will explore how depictions of these individuals can come to both reproduce and resist heavy metal masculine norms whilst not breaking from other heavy metal codes and values.

Representations of Ozzy Osbourne (for example see figure 3) on the cover of Kerrang! magazine tend to embellish themes of horror and madness. Particularly on issues 24 and 54 Osbourne is featured with make-up prosthetics and fangs, and his snarling features and exaggerated postures further emphasize these themes. Other depictions of Osbourne such as those on issues 221, 261 and 334 are much less extravagant in terms of costume although his horror-esque snarl is repeated on issue 221. On issue 224 he is presented with a more comical facial expression10 as he grips hold of a globe. His appearance on issue 334, a wide-angle photograph of Osbourne wearing what appears like a Fedora-style black hat and his trademark purple, round-frame shades, is what would likely be read as being likened to a hysterical madman trope. Horror, madness and goofiness are all themes that resonate with heavy metal values of rebelliousness in the sense that they are, in each their own ways, defined by marginalization from social respectability. In the fictional world of horror, creatures and mutations such as vampires and werewolves (both of which are referenced by Osbourne 
in these images) are most frequently depicted as aberrations in horror contexts: feared by "normal" people. They exist mostly at night in the cover of dark and, in the case of werewolves, symbolize an eruption of what is unwanted and repressed by the subject. Similarly, yet more grounded in reality, the trope of the madman also carries themes of marginalization since historically, those deemed to be mad or hysterical were expelled from society and confined to imprisonment (of some form or another). The clown/goofball trope on the other hand is someone who entertains, who is laughed at and who does not accept the seriousness of life. In this sense, goofiness depicted in the context of heavy metal instils the values of rebelliousness by rejecting the seriousness of respectable social life. Osbourne's masculinity in these depictions cannot be defined in terms of toughness, stoicism, machismo or other such typical masculine signifiers. Instead he resists these characteristics by emphasizing playfulness, rebelliousness and theatricality. Although he is depicted topless in some of these examples, he lacks any significant muscular definition that would signify hypermasculinity and the use of theatricality further distracts from the potential of this reading. Overall, although Osbourne's media persona certainly embodies the heavy metal values of rebelliousness, marginalization, horror, etc., any effort to regard Osbourne image as being typically masculinist will no doubt be superseded by the emphasis of his playfulness and theatricality.

Jon Bon Jovi is perhaps featured more frequently than any other artist throughout this period of Kerrang! magazine’s history (for example see figure 4). Depictions of Jon Bon Jovi on the cover of Kerrang! magazine reflect quite well Walser’s (1993) conclusions that Jon Bon Jovi successfully embodied the heavy metal values of power and freedom (associated with masculinity) and a romantic vulnerability appealing to 
female fans. Images of Jon Bon Jovi, especially those in the 1980s and very early 1990s, are thematically and aesthetically eclectic. In a similar way that Bon Jovi’s music is said to straddle between rock, pop and heavy metal, depictions of Jon Bon Jovi also defy strict categorization as typically masculine (on issue 92), feminine (on issue 204 and less so on issue 153), erotic and sexualized (on issue 128 and less so on issue 92) and quietly stoic (on issue 412). Regardless of this gender eclecticism, as illustrated in these examples, gender and/or sexuality almost always play a central thematic role. For instance, on issue 92 Jon Bon Jovi is depicted leaning over a pool table with a suggestive pout and clenched fists whilst a guitar is conveniently placed amongst pool balls. This image as a certain erotic and homoerotic energy suggested through his posture and clenched fists, while the use of the guitar is a reminder of masculine phallic power. Jon Bon Jovi’s vulnerability and sensitivity is aptly represented on issue 153 in which he is positioned in a slightly awkward and subdued pose amongst a pink fabric backdrop. His facial expression, stern yet contemplative, is not feminized, but it also resists masculine toughness. The visibility of the Superman logo tattoo seems to be an amusing reminder of his masculinity. Issue 412 depicts Jon Bon Jovi as being somewhat sombre yet stoic. Having dropped the long hair and elaborate clothing this image seems to avail any of heavy metal's distinctness, yet Jon Bon Jovi's masculinity is ensured through the exposure of his ample chest hair and stoicism. Representations of Jon Bon Jovi on the cover of Kerrang! magazine seem to reflect accurately Walser's analysis; however, Walser's conclusions about Jon Bon Jovi and his band centre on their accessibility and appeal to female fans. However, Jon Bon Jovi’s chameleon-like ability to adapt and transform through various gender categories reflects Clifford-Napoleone’s (2015) position on heavy metal masculinities, 
which reduced gender to pure performativity. Jon Bon Jovi’s abilities to transform his identity so fluidly are surely to have appeal to many male fans that do not identify so strongly with strict masculine norms.

As the founding member of Anthrax, Scott Ian is representative here of the thrash metal subgenre. As the heavier element of heavy metal (of this period) the thrash sound and attitude has become synonymous with masculinity and particularly masculinity as a symbolic weapon against homosexuality (Walser 1993: 130). In this sense, thrash metal is upheld by some as being a defence against the gender blurring associated with lighter heavy metal styles. My focus here is whether this sort of exclusive masculine heteronormativity is apparent when looking at how Scott Ian is represented in media images. Like Osbourne, Ian is not muscular or tall and for the majority of Ian's career he has, through either choice or genetics, brandished a bald head rather than the long hair that was so typical of the heavy metal look. This certainly sets Ian apart from most of his contemporaries and in particular makes his look more visible in the context of media exposure. Weinstein discussed how diversions from the heavy metal style code often found teasing remarks in the press and stated, perhaps somewhat comically, that 'the bald or even those who simply lack luxurious manes of hair are a disadvantage in heavy metal' (1991: 65). Ian certainly stands out in the context of Kerrang! magazine covers of this period (with perhaps only Pantera's Phil Anselmo being the only other significant depiction of baldness) and his stature has also earned him some flavourful remarks from the magazine (e.g. on issue 229 figure 5). Male hair loss has always been a concerning reality for some men (connections between hair loss and psychological distress are discussed in Wells et al. 1995; Conrad 2007) and this is perhaps more acutely 
experienced in the context of heavy metal in which long hair is recognized as the most primary visual signifier of metal-ness. In this sense, media exposure of bald heavy metal icons such as Ian no doubt helps to alleviate the potential of this distress. Although Brown et al. talk about how identification is formed through similarities of values this, I would suggest, can also be extended to similarities in respect to the body. These empathetic connections may indeed be much more potent in identification for those who see that certain celebrities have been through the same sorts of natural and irreversible changes. Aside from Ian's stature and baldness, he is most frequently depicted on Kerrang! magazine as a not-to-be-taken-seriously metal-head goofball. In fact, images of Scott Ian in this context could almost be stills lifted directly from movies such as Wayne's World and Airheads, being comical portrayals of heavy metal culture in the late 1980s and early 1990s. Humour and light-heartedness can also be seen in many of Anthrax’s early music videos (e.g. Madhouse) and live performances, which are attitudes perhaps inherited from other styles such as glam-metal. This approach was not shared by the other big thrash bands such as Metallica, Megadeth and Slayer, who all adopted much darker themes in their visual oeuvres. This visual mode of appearance exemplified by Ian contrasts the music style that is complex and aggressive and this spectacle of appearance helped to construct Ian's goofball media persona. Although this contrast can be difficult to interpret by readers insofar as the images may not meet what they expect to see in a thrash metal icon,11 in a sense, and similarly to Ian's bald look, what these images say is “it’s OK to be into serious music and not take life too seriously”. Ian’s distinct form of masculinity does not challenge heavy metal masculine norms in any striking way and it would be hard to imagine that a female metal icon could enact the same goofball persona 
in the media without suffering dismissal and criticism. However, depictions of Scott Ian with his bald look defies one of the key visual criteria of heavy metal masculinity at this time and combined with his notoriety and renown these images have helped to open up possibilities of new style codes.

In exploring here how masculinity is depicted in the media personas of three notable heavy metal icons I have shown that, in the context of magazine cover images, typically masculine gender codes such as machismo, hypermasculinity and aggression can be both reproduced and resisted. Analysing how heavy metal celebrity personas are constructed over a period of time has highlighted the potential to renegotiate and challenge some commonly held values of heavy metal culture whilst maintaining an overall heavy metal image. In this way, I argue that although heavy metal may well be masculinist in general (and this study finds substantial support for exscription especially), the sustained use of certain traits in heavy metal scholarship has done little to explain exactly what masculinity looks and feels like within heavy metal culture. Here, I show that looking at the distinct media personas of heavy metal icons so cherished within the scene can tell us about the possible ways that fans can use media images in making sense of their own gender and identity. Of course, the obvious limitation here is that this research rests entirely on media analysis and would benefit from interviews with heavy metal fans.

\section{Conclusion}

Here I have shown how characteristics of heavy metal masculinities have been depicted on the cover of Kerrang! magazine not in individually selected examples but over an extended period. And through this I have drawn some conclusions. My first conclusion, 
as addressed through the content analysis, is that the use of certain masculine traits in heavy metal scholarship is inadequate in defining what masculinity is in the context of heavy metal. This was shown by firstly establishing that heavy metal magazines such as Kerrang! in many ways uphold the values and codes of heavy metal culture (Weinstein 1991; Brown 2007; Hill 2016) and subsequently demonstrating through content analysis that the frequency by which these traits are depicted on the cover of Kerrang! magazine does not adequately reflect the prominence that they appear in heavy metal scholarship. Subsequently, in acknowledging that media saturation is not the only way that traits can come to define masculinity I used a qualitative visual analysis approach, drawing on celebrity identification theory, to explore how the mediated personas of three prominent heavy metal icons show how heavy metal masculine norms can be resisted without defying heavy metal values in general. Through this, I conclude that media images depicting celebrity personas can be used by audiences in negotiating and making sense of their own gender and identities. Whilst other authors (Brown 2007; Brown cited in Scott and Von Helden 2010; Hill 2016) have focussed mostly on reader contributions and editorial content to form their conclusions, I have focussed entirely on visual content on the magazine cover. Whilst it could always be questioned if readers (especially passive readers) actually actively engage with the magazines’ written content, it would be safe to assume that all readers see12 the images on offer and as such these images act over time to form an over-arching picture of what heavy metal culture looks like. Overall, I hope to have shown that, whilst uses of masculine traits in heavy metal scholarship can help to visualize for the reader what masculinity looks like in heavy metal culture, they are perhaps too strict and static to be particularly helpful. Furthermore, whilst there has been 
much valuable work done on the experiences of women and other marginalized groups in heavy metal scholarships, there is perhaps still room for more discussion about male fans and their experiences of masculinity. And, until this research has been established, it would appear that male experiences will continue to be situated by scholars as being "normal".

Figure 1: Kerrang! Magazine Issue 291 featuring James Hetfield. (C) Wasted Talent Publishing.

Figure 2: Kerrang! Magazine Issue 182 featuring Joe Elliott. (c) Wasted Talent Publishing.

Figure 3: Kerrang! Magazine Issue 24 featuring Ozzy Osbourne. (c) Wasted Talent Publishing

Figure 4: Kerrang! Magazine Issue 153 featuring Jon Bon Jovi. @ C Wasted Talent Publishing

Figure 5: Kerrang! Magazine Issue 229 featuring Scott Ian. ( ) Wasted Talent Publishing

\section{References}

Beyton, M. (1997) 'Women and the Electric Guitar’, in Whiteley, S. (ed), Sexing The Groove: Popular Music and Gender, New York: Routledge, pp. 37-49.

Boise, S. De (2015), Men, Masculinity, Music and Emotions, London: Palgrave.

Brown, A. R. (2007), ‘Everything louder than everything else’, Journalism Studies, 8:4, pp. 642-55. (2010), 'The importance of being metal: The metal music tabloid and youth identity construction', in Scott, N. and Von Helden, I. (eds), The Metal Void: First Gatherings, Oxford: Inter-disciplinary press, pp. 105-34. 
_ (2016), “'Girls like metal, too!” female reader’s engagement with the masculinist culture of the tabloid metal magazine', in Heesch, F. and Scott, N. (eds), Heavy Metal, Gender and Sexuality: Interdisciplinary Approaches, London: Routledge, pp. 163-81.

Brown, W. J., Basil, M. D. and Bocarnea, M. C. (2003), 'Social influence of an international celebrity: Responses to the death of Princess Diana', Journal of Communication, 53:4, pp. 587-605.

Brown, W. J. and Fraser, B. P. (2003), 'Celebrity identification in entertainment education', in Singhal, A., Cody, M. J., Rogers, E. M.and Sabido, M (eds), Entertainment-Education and Social Change: History, Research and Practice, London: Routledge, pp. 97-115.

Clifford-Napoleone, A. R. (2015), Queerness in Heavy Metal Music: Metal Bent, London: Routledge.

Coates, N. (1997) '(R)Evolution Now?: Rock and the Political Potential of Gender', in Whiteley, S. (ed), Sexing The Groove: Popular Music and Gender, New York: Routledge, pp. 50-64.

Cohen, S. (1997) 'Men Making a Scene: Rock Music and the Production of Gender’, in Whiteley, S. (ed), Sexing The Groove: Popular Music and Gender, New York: Routledge, pp. 12-36.

Conrad, P. (2007) The Medicalisation of Society: On the Transformation of Human Conditions. Maryland: Johns Hopkins University Press.

Cope, A. L. (2010), Black Sabbath and the Rise of Heavy Metal Music, Farnham: Ashgate Publishing. 
Dyer, R. (1998), Stars. London: BFI Publishing.

Elfein, D. (2016), 'Never say die! Ozzy Osbourne as a male role model’, in Heesch, F. and Scott, N. (eds), Heavy Metal, Gender and Sexuality: Interdisciplinary Approaches, London: Routledge, pp. 71-83.

Fraser, B. P. and Brown, W. J. (2002), 'Media, celebrities and social influence: Identification with Elvis Presley’, Mass Communication and Society, 5:2, pp. 183-206.

Heesch, F. and Scott, N. (eds) (2016), Heavy Metal, Gender and Sexuality: Interdisciplinary Approaches, London: Routledge.

Hill, R. L. (2016), Gender, Metal and the Media: Women Fans and the Gendered Experience of Music, London: Palgrave.

Kaplan, A. E. (1987), Rocking around the Clock: Music Television, Postmodernism and Consumer Culture, London: Methuen Publishing.

Nordstrom, S. and Herz, M. (2013), 'It’s a matter of eating or be eaten: Gender positioning and difference making in the heavy metal subculture', European Journal of Cultural Studies, 16:4, pp. 453-67.

Riches, G. (2015), ‘Re-conceptualising women’s marginalization in heavy metal: A feminist post-structuralist perspective’, Metal Music Studies, 1:2, pp. 263-70.

Riches, G., Lashua, B. and Spracklen, K. (2014), 'Female, mosher, transgressor: A moshography of transgressive practices within the Leeds extreme metal scene', IASPM Journal, 4:1, pp. 87-100.

Schippers, M. (2002), Rockin’ Out of the Box: Gender Maneuvering in Alternative Hard Rock, New Brunswick, NJ: Rutgers University Press. 
Scott, N. and Von Helden, I. (eds) (2010), The Metal Void: First Gatherings, Oxford: Inter-disciplinary press.

Sollee, K. (2011), 'Hysteric desire: Sexual positions, sonic subjectivity and gender play in glam metal', in McKinnon, C., Scott, N. and Sollee, K. (eds), Can I Play with Madness: Metal Dissonance, Madness and Alienation, Oxford: Inter-disciplinary press, pp. 51-62.

Vasan, S. (2011), 'The price of rebellion: Gender boundaries in the death metal scene', Journal for Cultural Research, 15:3, pp. 333-49.

Walser, R. (1993), Running with the Devil: Power, Gender and Madness in Heavy Metal Music, Middletown, CT: Wesleyan University Press.

Ward, S. (n.d.), 'Geoff Barton, behind the wheel', http://www.rockcriticsarchives.com/interviews/geoffbarton/geoffbarton.html. Accessed 4 June 2017.

Weinstein, D. (1991), Heavy Metal: A Cultural Sociology, New York: Lexington Books.

_ (2016), 'Playing with gender in the key of metal', in Heesch, F. and Scott, N.

(eds), Heavy Metal, Gender and Sexuality: Interdisciplinary Approaches, London: Routledge, pp. 11-25.

Wells, P. A., Willmoth, T. and Russell, R. J. (1995), 'Does fortune favour the bald? Psychological correlates of hair loss in males’. British Journal of Psychology, 86: 337-344.

Whiteley, S. (ed.) (1997), Sexing the Groove: Popular Music and Gender, London: Routledge. 
1. For consistency images were sourced exclusively from crazyaboutmagazines.com.

2. A random sample of 138 images were analysed from a total of 231 containing sole-male images. The sample represented 99 per cent confidence level and 7 per cent margin of error.

3. A pilot test subsample of twenty images was used to assess inter-coder reliability. Using Krippendorf's Alpha reliability coefficient returned fifteen of seventeen original features as being reliable. Of the two that returned $<0.65$ for reliability 1 feature was removed (corporeal energy) as it was seen to be too complex to be easily coded and the other (elaborate hair) required further discussion in terms of what constituted 'elaborate'. 4. I have chosen to use cover images since the magazine cover is a feature of the magazine that is perhaps overlooked in heavy metal scholarship. Although Brown (2016) does look at covers briefly, this is secondary to analysing reader content.

5. Although his analysis is quite weak, overall Elfein (cited in Heesch and Scott 2016) contrasts Osbourne’s masculinity to others stating that his analysis 'contains weaker and softer elements’ (p. 71).

6. And we should not forget that while female fans may negotiate their gender positions to identify with masculinities, male fans may also actively seek to negotiate their identities away from masculine norms.

7. More than 30 per cent was identified as demonstrating a significant frequency.

8. Of course, this study is limited only to those present on the cover of Kerrang! magazine and therefore is not fully representative of the ways that certain traits could be adopted by fans and represented in other magazines. 
9. Approaches to image analysis in heavy metal scholarship would tend to look at a small number, if not single, images out of the context of overall media saturation.

10. The lack of seriousness in Osbourne's appearance as he grips hold of a globe on this issue is ironically offset against the sombre mood of the associated copy 'I had the whole world in my hands: Ozzy speaks from rehab’.

11. Visual codes and aesthetics associated with specific heavy metal subgenres have always played a role in situating bands and artists within the spectrum of heavy metal styles and as such there would necessarily be expectations of how certain individuals would look and act depending on their subgenre classification.

12. Of course, how much conscious image reading is done is also dependent on the reader's level of engagement in the content as a whole.

Simon Jones has asserted his right under the Copyright, Designs and Patents Act, 1988, to be identified as the author of this work in the format that was submitted to Intellect Ltd. 